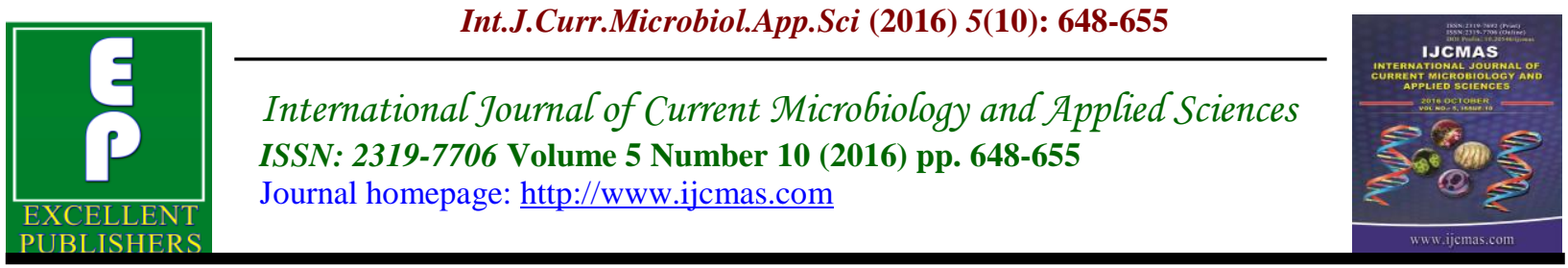

Original Research Article

http://dx.doi.org/10.20546/ijcmas.2016.510.072

\title{
Effect of Aqueous Extract of Annona muricata (Graviola Tea) on the Oxidative Stress produced by the Artificial UV Source in Vivo and in Vitro
}

\author{
Bhaumik D. Vaghela*, Devarshee Bhavsar and Nayan K. Jain \\ Department of Life Sciences, Gujarat University, Ahmedabad, Gujarat, India \\ *Corresponding author
}

A B S T R A C T

Keywords

Blood samples, graviola tea, oxidative stress, rats,

UV exposure.

\section{Article Info}

Accepted:

20 September 2016

Available Online:

10 October 2016
The prime purpose of the study was to investigate the effects of Graviola tea on the oxidative stress induced by the ultraviolet light. In the in vivo part, the rats were divided into the three groups of six animals each. The $1^{\text {st }}$ group in which healthy animals (Control), $2^{\text {nd }}$ group in which only UV treatment was given to the animals (Non-treated), $3^{\text {th }}$ group in which Graviola tea was given after UV exposure to the animals (Treated) and for in vitro part, blood samples were collected group wise i.e. i) Control which contains blood sample of healthy individuals, ii) Non treated group in which blood samples were exposed to UV radiation for different time intervals and in the iii) Treated group blood sample were exposed to UV radiation and subsequently treated with graviola tea for different time intervals under aseptic conditions. Then the biochemical assays like Lipid Peroxidation, Protein Carbonyl Oxidation, Superoxide Dismutase, Catalase, Glutathione Peroxidase were performed and positive results were obtained.

\section{Introduction}

The primary source of the ultraviolet radiation is the solar radiation for all the living system. UV rays have the range of $100-400 \mathrm{~nm}$. UV radiation can be divided into three categories based on the wavelength I) UV A: $315-400 \mathrm{~nm}$, II) UV B: $280-315 \mathrm{~nm}$, III) UV C: $100-280 \mathrm{~nm}$ as said by International Commission on Illumination (Duthie et al., 1999; Clydesdale et al., 2001). Ultraviolet radiation has a few helpful health effects like use in the treatment of vitiligo along with the combination of drugs and helps in vitamin $\mathrm{D}_{3}$ formation. Ultraviolet radiation plays a vital role in the initiation of some pathological conditions in skin. Ultraviolet radiation is considered the major cause of erythema, pigmentation, immunosuppression and delayed effects are skin aging, DNA damage and skin cancer (Kligman, 1989; Matsui and Leo, 1991; Hussein, 2005). Ozone layer absorbs UV radiation up to $310 \mathrm{~nm}$. Thus it absorbs all UV $\mathrm{C}$ and most of the UV B but does not absorbs UV A (Gruijl and Van der Leun, 2000). In the skin because of the reaction of UV photons with endogenous photosensitizers more of Reactive Oxygen 
Species (ROS) is produced which may disturb the antioxidant protective mechanisms ending in the antioxidant/ prooxidant disequilibrium known as oxidative stress (Heck et al., 2004).

ROS are inseparable and natural component of metabolism. Fibroblasts and keratinocytes constantly generate ROS in the skin and swiftly removed by enzymic antioxidant like glutathione reductase, superoxide dismutase, glutathione Peroxidase, catalase and non enzymic antioxidants like glutathione, tocopherol, ascorbic acid and ubiquinol that sustain the anti-oxidant/ pro-oxidant balance, thus resulting in tissue and cell stabilization (Sander et al., 2004; Inal et al., 2001). As UV A is having long wavelength compared to UV B and UV C, UV A can penetrate much deep in the skin. In the humans UV A is more vital to cause skin inflammation than UV B (Nishigori et al., 2004). Oxidative damage to the DNA can be increased as inflammatory cells generate ROS (Halliday, 2005). UV A has a bigger influence on oxidative stress than UV B in the skin as UV A can induce RNS/ROS which can damage lipids, proteins and DNA and also lead to depletion of NADH and hence loss of energy from the cell (Halliday, 2005).

Annona muricata Linn is commonly known as soursop or graviola, belongs to the family of Annonaceae. It is a tropical tree and native of Central America. The leaves are dark green in color and glossy that had been conventionally used to treat asthma, headaches, cough, hypertension, and used as sedative, antispasmodic and anti-fungal activity (Taylor, 2002). The phytochemicals found in Annona muricata are flavonoids, alkaloids, tannins, saponins, terpenoids, phytosterol, cardiac glycosides, proteins and carbohydrates and annonaceous acetogenins.

\section{Materials and Methods}

The study was divided into two parts of in vivo and in vitro.

\section{In vivo part}

The study was aimed to check the effect of Graviola tea on the oxidative stress induced rats.

\section{Animal care and Monitoring}

The present study was carried out on healthy adult male and female rats of Albino Wistar strains weighing of approximately 150200gm obtained from inbred colony maintain in animal house of Sardar Patel University where rats were housed 1 per cage in polypropylene cages that were fitted with stainless steel wire mesh bottom under standard laboratory condition $25 \pm 5^{\circ} \mathrm{C}$ temperature, $50 \pm 15 \%$ relative humidity and $12 \pm 3 \mathrm{hr}$ dark and light photoperiod. The animals were given standard food pellets and water ad labium throughout the period of experiment. The animals used in present study were maintained and handled according to the University and Institutional Legislation, regulated by the committee for the purpose of Control and Supervision of Experiments on Animals (CPCSEA), Ministry of Social Justice and Empowerment, Government of India and Institutional Animal Ethics committee (IAEC) of Sardar Patel University, V.V.Nagar, Anand, Guajrat. The experimental protocol was approved by the IAEC.

Animals were randomized into four groups of six rats each:

Group I: No treatment given. Healthy (Control) 
Group II: Animals were given UV exposure for 21 days. (Non-treated)

Group III: Animals were given UV exposure for 21 days and then given Graviola extract of $3 \mathrm{ml}$ for 15 days. (Three times in a day) (Treated)

\section{Irradiation treatment}

Rats were shaved in a $6 \times 8 \mathrm{~cm}^{2}$ of dorsal area. Any damage to the animal skin was carefully avoided. The UV exposure was given for 1 hour. The ultraviolet light was used with a wave length starting from 290 to $315 \mathrm{~nm}$, at a distance of $5 \mathrm{~cm}$ from the skin.

\section{Equipment}

Ultraviolet lamps from Blackwood present a $220-230 \mathrm{~V}$ connection. UV lamps were fitted into the spot light dome and the according to that stands were made. The cages were made from stainless steel grill.

\section{Sample preparation for in vivo study}

The skin tissues were minced with the help of a scissors and homogenized in ice cold $50 \mathrm{mM}$ phosphate buffers ( $\mathrm{pH}-7.4)$ by potter and elvejem type homogenizer equipped with a Teflon pestle (Remi motor, Bombay) to obtain homogenate. The debris was removed by centrifuge at $10,000 \mathrm{rpm}$ for 15 minutes at $4^{\circ} \mathrm{C}$ in cooling centrifuge (Hettich Zentrifuge, Germany). The clear supernatant was used for all the biochemical parameters of oxidative stress.

\section{In Vitro part}

$5 \mathrm{ml}$ of blood from the normal healthy males aged between 25-30 years was collected and then various biochemical test were carried out and those who have normal range of oxidation only those blood samples were considered as samples. A total of 30 blood samples were considered. From those samples $500 \mu 1$ of blood was distributed evenly in small petri plates. Two sets were made named treated and untreated. The UV radiation was given to the timing of 3 minutes, 6 minutes, 9 minutes and 12 minutes in duplicates under aseptic conditions. The $125 \mathrm{~W}$ black bulb was used as the radiation source at the distance of 5 $\mathrm{cm}$. The luminance flux measured using the Lux meter was $205 \pm 3$ Lux or Lumen $/ \mathrm{m}^{2}$. After UV exposure treated set was cultured with $8 \mathrm{ml}$ of RPMI- 1640 media and $1 \mathrm{ml}$ of graviola tea. The untreated set was cultured with $8 \mathrm{ml}$ of RPMI- 1640 media only. For control, no irradiation was applied to the blood sample and was directly added to the culture media.

\section{Cell Culture}

All the samples were cultured for 48 hours in the incubator. . The medium has PHA-M, streptomycin and penicillin. Culture conditions were maintained at $37^{\circ} \mathrm{C}$ using incubator.

\section{Sample Preparation for in vitro study}

After 48 hours of culturing, the cells were harvested by centrifuging the culture tubes at $2000 \mathrm{rpm}$ for 20 minutes. The supernatant was discarded and same volume of hypotonic solution of $\mathrm{KCl}(0.5 \% \mathrm{KCl})$ was added and gently mixed with the pellet of cells followed by incubation of 20 minutes at $37^{\circ} \mathrm{C}$. The cell lysate thus obtained was used as sample for all the biochemical assays performed. All the assays were performed in triplicates.

\section{Collection of the plant samples}

Plant sample (Annona muricata) was collected from a nursery in Bangalore, 
Karnataka. The leaves and stems were washed with distilled water. The leaf and small pieces of stems were dried in the shade.

\section{Graviola tea procedure}

In the glass bowl take 1 liter of distilled water and then add 30 graviola dried leaves and add 4 small pieces of stem and start boiling the water. Then boil water until $900 \mathrm{ml}$ of water remains in the bowl. Cool it.

\section{Biochemical assays}

In this study, the following biochemical tests were performed as per standard operating procedure.

\section{Lipid Peroxidation}

The Thiobarbituric Acid Reactive Substances (TBARS) as a product of unsaturated fatty acid in the tissue was measured according to method described by (Ohkawa et al., 1979).

\section{Glutathione Peroxidase}

The glutathione peroxidase activity was checked by the method of (Rotruck et al., 1973)

\section{Protein Oxidation}

Determination from protein oxidation is chemically stable and serves as markers of oxidation. Estimation of protein carbonyl (PCO) content: Protein carbonyl (PCO) was measured by using the method of (Reznick and Packer et al., 1994).

\section{Superoxide dismutase}

SOD activity was measured by quantifying the inhibition of NBT transformation to formazan, applying the process of (Kakker et al., 1984).

Catalase

The catalase activity was measured by the method of (Sinha, 1972).

\section{Statistics}

The entire experiment was performed in triplicates and the data were described as mean \pm standard deviation (SD). Statistical study was carried out by one -way ANOVA. Level of signification was determined by Graphpad Prism 5.0 (USA) and was found to be $\mathrm{P}<0.05$.

\section{Results and Discussion}

\section{In vivo part}

\section{Protein carbonyl content and Lipid peroxidation}

In the protein oxidation there was $66 \%$ increase from control in the non treated group where as $34 \%$ increase from control in treated group. In the lipid peroxidation there was $58 \%$ increase compare to control in the non treated group and $25 \%$ increase from control in the treated group. 


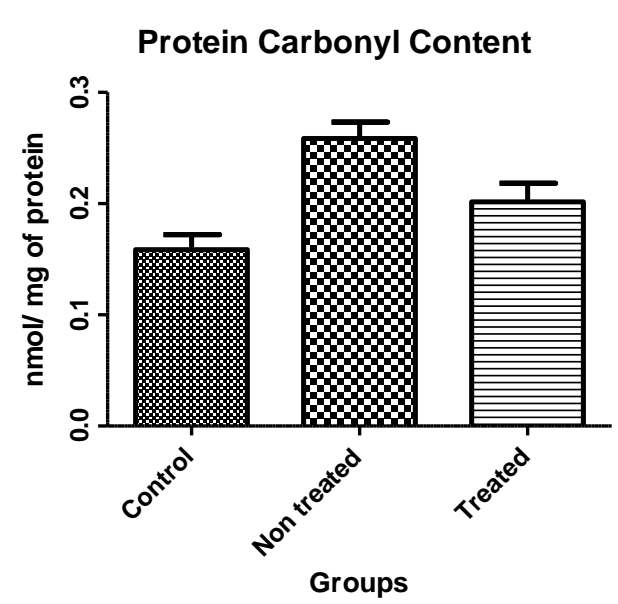

Superoxide dismutase and Catalase

In superoxide dismutase and catalase there was $47 \%$ and $42 \%$ decrease from control in

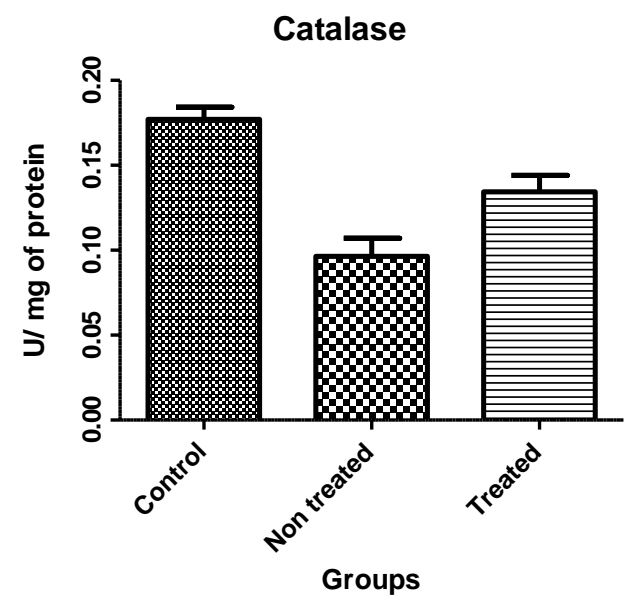

In vitro part

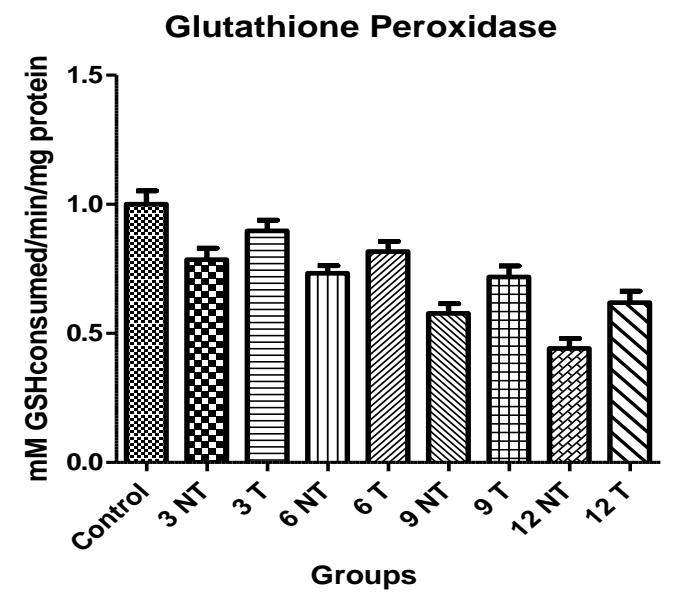

Lipid Peroxidation

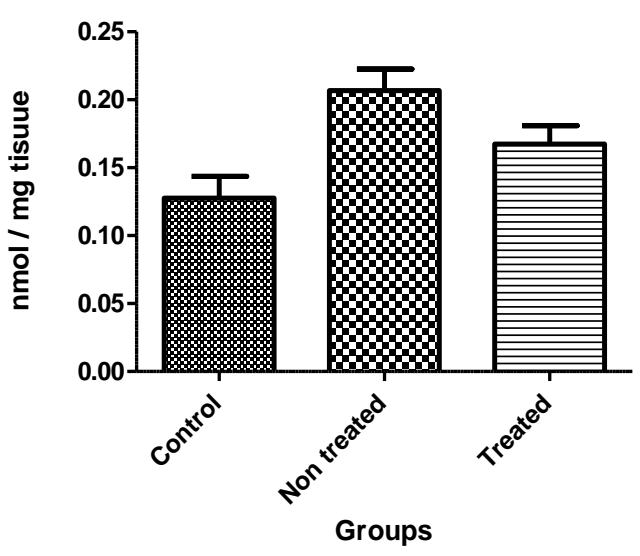

the untreated group respectively where as $23 \%$ and $26 \%$ decrease compare to control in treated group in superoxide dismutase and catalase

respectively.

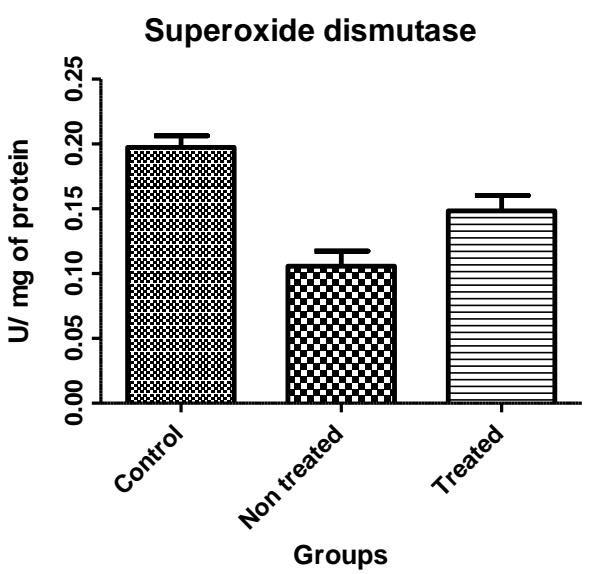

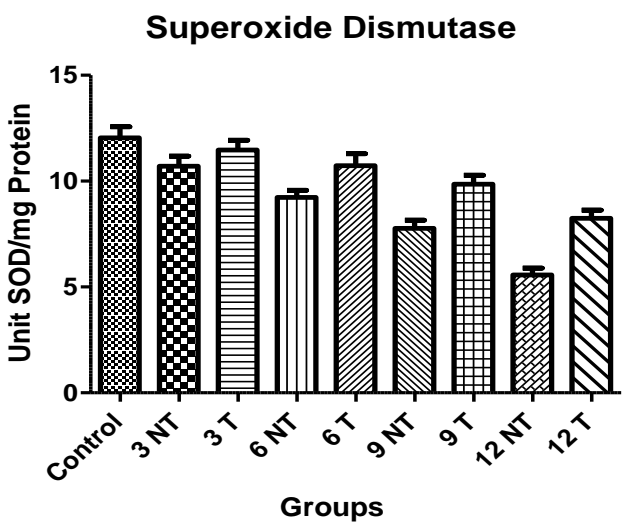


3NT (Non Treated) - Only 3minutes of UV radiation and $3 \mathrm{~T}$ (Treated) - 3minutes of UV radiation and later treated with graviola extract; Same applies to the rest.

Glutathione Peroxidase: There was $21 \%$ decrease in $3 \mathrm{NT}$ where only $11 \%$ decrease in $3 \mathrm{~T}$ and $27 \%$ decrease in $6 \mathrm{NT}$ and $19 \%$ decrease in $6 \mathrm{~T}$ furthermore $43 \%$ decrease in

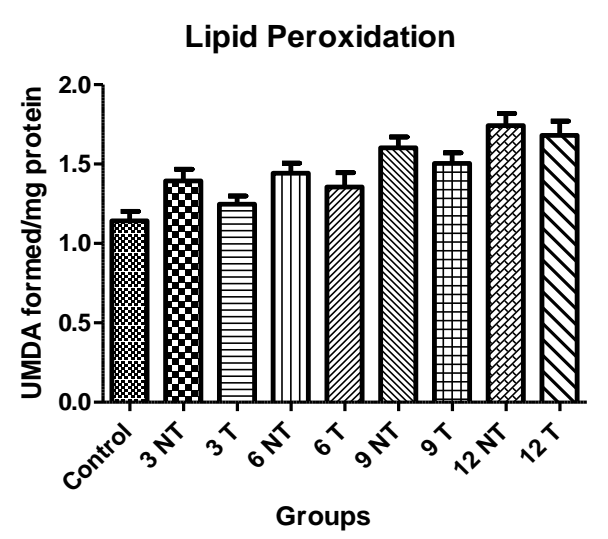

Lipid peroxidation: it was observed $18 \%$ increase in $3 \mathrm{NT}$ and $10 \%$ increase in $3 \mathrm{~T}$ compare to control along with $27 \%$ increase in $6 \mathrm{NT}, 17 \%$ increase in $6 \mathrm{~T}$ futher more $45 \%$ increase in $9 \mathrm{NT}$ and $36 \%$ increase in 9T moreover, $54 \%$ increase in $12 \mathrm{NT}$ and $45 \%$ increase in $12 \mathrm{~T}$.

Catalase: There was $10 \%, 18 \%, 24 \%, 31 \%$ decrease in 3NT, 6NT, 9NT and 12NT correspondingly where as $4.5 \%, 8 \%, 14 \%$, $21 \%$ decrease in 3T, 6T, 9T and $12 \mathrm{~T}$ respectively compare to control.

From the centuries, plants are investigating for their diverse therapeutic properties that might be successful in management, prevention, and cure of various diseases. Naturally occurring compounds are proving a better choice than synthetic compounds as naturally occurring compounds have lesser side effects.

Phytochemicals that have a definite physiological function are important factors
9NT and 30\% decrease in 9T moreover 56\% decrease in $12 \mathrm{NT}$ and $39 \%$ decrease in $12 \mathrm{~T}$.

Superoxide dismutase: It was $11 \%, 23 \%$, $35 \%, 55 \%$ decrease in $3 \mathrm{NT}, 6 \mathrm{NT}, 9 \mathrm{NT}$ and $12 \mathrm{NT}$ respectively where as $5 \%, 11 \%, 18 \%$ , $32 \%$ decrease in $12 \mathrm{~T}$ respectively compare to control.

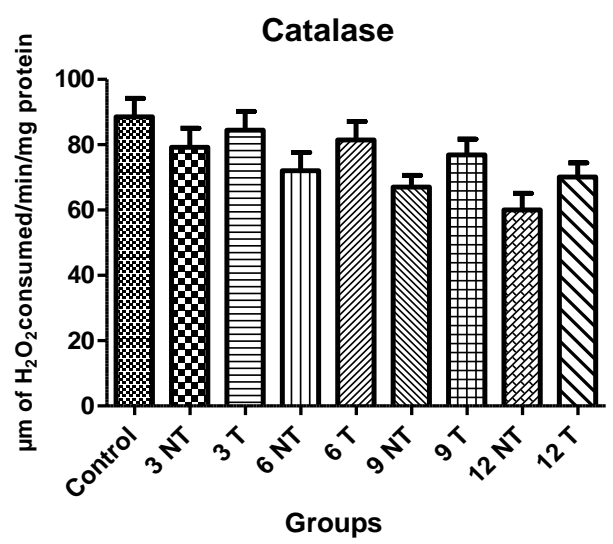

to decide the medicinal value of a plant. The most significant phytochemicals are phenolic compounds, tannins, flavonoids, alkaloids (Hill, 1952). Flavonoids work as antioxidants and are known to boost the Vitamin C's effects. They are biologically active against microbes, viruses, tumors, liver toxins (Korkina et al., 1997). Tannins possess anti-oxidants activities (Tebib et al., 1997). Tannins and flavonoids belong to the phenolic compounds and plant phenolic compounds are a chief group that acts as free radical scavengers or prime antioxidants (Polterait, 1997). The amounts of total phenolics in the extract was quantified and found to be significantly higher. In the study by (Vijayameena et al., 2013) had proved that aqueous extract of A.muricata shows non enzymatic antioxidants like Vit.C and Vit $\mathrm{E}$ and enzymatic antioxidants like SOD and Catalase. The prior study by (Baskar et al., 2007) had shown that leaf ethanolic extract of graviola exhibits considerable antioxidant property so A.muricata possess anti oxidative activity may be credited to 
annonaceous acetogenins. The aqueous extract of Annona muricata (Graviola tea) has shown considerable antioxidant potentials in this experiment. However, further investigation should be carried out to make sure it's safe usage.

Conflict of Interest: The authors declare that they have no conflict of interest.

\section{References}

Baskar, R., Rajeswari, V., Kumar, T.S. 2007. In vitro antioxidant studies in leaves of annona species. Indian $J$. Exp. Biol., 4: 480-5.

Clydesdale, G.J., Dandie, G.W., Muller, H.K. 2001. Ultraviolet light induced injury: Immunological and inflammatory effests. Immunol. Cell Biol., 79: 547-68.

De Gruijl, F.R., Van der Leun, J.C. 2000. Environment and health: 3. Ozone depletion and ultraviolet radiation. CMAJ, 163: 851-5.

Duthie, M.S., Kimber, I., Norval, M. 1999. The effects of ultraviolet radiation on the human immune system. Br. J. Dermatol., 140: 995-1009.

Halliday, G.M. 2005. Inflammation, gene mutation and photoimmunosuppression in response to UVRinduced oxidative damage contribute to photocarcinogenesis. Mutat. Res., 571: 107-20.

Heck, D.E., Gerecke, D.R., Vetrano, A..M, Laskin, J.D. 2004. Solar Ultraviolet light induced alteration to the skin ultraviolet radiation as a trigger of cell signal transduction. Toxicol. Appl. Pharmacol., 195: 288-97.

Hill, A.F. 1952. Economic Botany. A textbook of useful plants and plant products. 2nd edn. McGarw-Hill Book Company Inc, New York.

Hussein, M.R. 2005. Ultraviolet radiation and skin cancer: molecular mechanisms. J. Cutan. Pathol., 32: 191-205.

Inal, M.E., Kahramant, A., Kökent, T. 2001. Beneficial effects of quercetin on oxidative stress induced by ultraviolet A. Clin. Exp. Dermatol., 26: 536-9.

Kakkar, P., Das, B., Viswanathan, P.N. 1984. A modified spectrophotometric assay of superoxide dismutase, Ind. J. Biochem. Biophys., 21: 130-132.

Kligman, L. 1989. The ultraviolet-irradiated hairless rat: a model for photoaging, $J$. Am. Acad. Dermatol., 21: 623-63I .

Korkina, L.G., and Afanas'ev, I.B. 1997. Antioxidant and chelating properties of flavonoids. Adv. Pharmacol., 38: 15163.

Matsui, M. and V. De Leo. 1991. Longwave ultraviolet radiation and promotion of skin cancer, Cancer Cells, 3: 8-12.

Nishigori, C., Hattori, Y., Toyokuni, S. 2004. Role of reactive oxygen species in skin carcinogenesis. Antioxid. Redox. Signal, 6: 561-70.

Ohkawa, H., Ohishi, N., Yagi, K. 1979. Assay for lipid peroxides in animal tissues by thiobarbituric acid reaction Anal. Biochem., 95: 351-358.

Polterait, O. 1997. Antioxidants and freeradical scavengers of Natural Origin. Curr. Org. Chem., 1: 415-40.

Reznick, A.Z., Packer, L. 1994. Oxidative damage to proteins: spectrophotometric method for carbonyl assay, Methods Enzymol., 233: 357-63.

Sander, C.S., Chang, H., Hamm, F., Elsner, P., Thiele, J.J. 2004. Role of oxidative stress and the antioxidant network in cutaneous car- cinogenesis. Int. J. Dermatol., 43: 326-35.

Sinha, A.K. 1972. Colorimetric assay of catalase, Anal. Biochem., 47(2): 38994. 
Taylor, L. 2002. Technical data report for graviola, annona muricata. Sage Press. Austin, 10: 1-6.

Tebib, K., Rouanet, J.M., Besançon, P. 1997. Antioxidant effects of dietary polymeric grape seed tannins in tissues of rat fed a high cholesterol- vitamin E-deficient diet. Food Chem., 59:
$135-141$.

Vijayameena, C., G. Subhashini, M. Loganayagi and B. Ramesh. 2013. Phytochemical screening and assessment of antibacterial activity for the bioactive compounds in Annona muricata, Int. J. Curr. Microbiol. Appl. Sci., 2(1): 1-8.

\section{How to cite this article:}

Bhaumik D. Vaghela, Devarshee Bhavsar and Nayan K. Jain. 2016. Effect of Aqueous Extract of Annona muricata (Graviola Tea) on the Oxidative Stress produced by the Artificial UV Source in Vivo and in Vitro. Int.J.Curr.Microbiol.App.Sci. 5(10): 648-655. doi: http://dx.doi.org/10.20546/ijcmas.2016.510.072 